\title{
Chapter 1: \\ The Effectiveness of Symbols: Mediology and Hermeneutics
}

\section{Introduction}

As I explained in the Introduction, my approach in this book combines social theory of action and hermeneutics. The term "hermeneutics" is not new in social theory - it is often used in expositions of comprehensive sociological theories. ${ }^{1}$ However, the integration of the philosophical subdiscipline of hermeneutics into social theories is still sometimes met with scepticism. Is philosophical hermeneutics not the study of how to read texts? Is it not fatally bound to tradition? In this chapter, I want to pre-empt this possible objection and in this way also take the first steps in explicating my approach to action.

Hermeneutics did indeed start out as the study of thorough reading. But more than a century's philosophical research has expanded the field of hermeneutics to include all aspects of human reality. Action is certainly included. My primary interlocutor in this book, Paul Ricœur, is one of the philosophers who mastered the scholarly tradition of hermeneutics, but expanded it explicitly to a hermeneutics of agents and action, or as he often said, the acting and suffering human. The title of his book, From Text to Action, succinctly captures this point this book is our major reference to his work in the present chapter. Making action an object of hermeneutic study simply means that it is studied not as a series of impersonal events, but as forms of doings that have meaning for those concerned in and by it. Here, hermeneutics is thus the study of meaning in action and of the interpretation of action. Accordingly, Ricœur's hermeneutics of human capabilities (also called a hermeneutics of the capable human) will remain with us throughout this book. ${ }^{2}$ However, instead of simply proclaiming the usefulness of a hermeneutic approach to a social theory of action, I would like to defend it. In order to do so, I chose as my second interlocutor in this chapter someone who has explicitly expressed his doubts about the value of hermeneutics: Régis Debray. ${ }^{3}$ Debray is an interesting fencing partner for two very spe-

1 See, for instance, the Gadamer-Habermas debate of half a century ago.

2 See the sort introduction to the hermeneutics of human capabilities in Chapter 3, §1.

3 My point is neither to exaggerate his importance as social scientist, nor to use him simply as a weak opponent.

Ә OpenAccess. ( 2021 Ernst Wolff, published by De Gruyter. (cc) BY-NC-ND This work is licensed under the Creative Commons Attribution-NonCommercial-NoDerivatives 4.0 License. 
cific reasons: for one thing, he had an eventful career of political action behind him $^{4}$ before he started developing the theory which interests us here; for another, he offered an alternative view on texts from that of hermeneutics, namely mediology. My first aim in engaging with his thought, then, is to demonstrate that hermeneutics, in the broad sense adopted here, is linked to human practice from the beginning. My second aim is to do so by starting from the (historical) core concern of hermeneutics: texts and text-like phenomena.

From the wealth of human capabilities and action, we can narrow down our view to the production and reception of utterances in language. If I can demonstrate that hermeneutics is integrally linked with concerns of action even in this apparently linguistic core, then we have good reason to assume that hermeneutics is integrally linked with human action wherever we may want to explore it. This chapter's focus on speech, texts and transmission is therefore intended as a starting point from which to indicate the full expansion of the approach that I follow in the other chapters.

\section{Enter Mediology}

But I need clarify my particular interest in Debray's project a bit further. One may consider his theory of mediology as an exciting new actor on the stage on which language and linguistic phenomena are being presented. ${ }^{5}$ The unique promise of mediology is that it will clarify the transmission of meaning as an aspect of language. This contribution has to take its place in the drama of love and conflict between semiology, linguistics, communication theory, the theory of literature and other disciplines that are evaluated by the community of academic spectators.

At times, however, one gets the impression that Debray is determined to deny hermeneutics (as one of the other actors) its claim to a place on the stage. His dismissive references to hermeneutics create the impression that mediology stands in opposition to hermeneutics, or is at least totally separated from

4 Cf. Keith Reader, Régis Debray: A Critical Introduction (London: Pluto, 1995) and Jean Tellez, L'âme et le corps des idées. Introduction à la pensée de Régis Debray (Meaux: Germina, 2010), $39-115$.

5 For background see Frédéric Vandenberghe, "Régis Debray and Mediation Studies, or How Does an Idea Become a Material Force?” Thesis Eleven 89, no. 1 (2007): 23-42, here 23-25; the same article is also a useful overview of mediology. Maryam Bolouri, Medial Transformations: Theorising the Intelligent Mediation Sphere (Tübingen: Eberhard Karls-Universität Tübingen 2019) situates Debray in relation to other media theories. 
it. $^{6}$ Admittedly, it is necessary to define the mediological perspective in order to give it its own voice within the "council of disciplines". ${ }^{7}$ But it is equally important to go further than insisting on "why we are not ..." if we want to prevent the council from becoming a cacophony of monologues. Besides, this opposition does not sit well with the orientation of mediology as one of several valid perspectives on reality. Rather, the search for dialogue is a defining characteristic of the methods of mediology. Louise Merzeau summarises this openness, which is reflected in many of the articles in the Cahiers de Médiologie and in Médium, ${ }^{9}$ when she states that mediology

is averse to practicing exclusion. Anyone who would like to explore it can do so, without necessarily forfeiting their membership of their original discipline. [...] Double lanes are even strongly recommended, since it is true that mediology cannot be practised in the self-sufficiency of institutionalized knowledge. [...] [M]ediology must cultivate its impurity in order to guarantee its effectiveness."10

The nature of the mediological perspective is such that it offers a perspective on other fields of study, while at the same time it is subjected to the perspectives of those other fields. ${ }^{11}$ However, this gives us more than only two perspectives, since a successful dialogue produces more than the two original viewpoints, without their being dissolved in a harmonious whole. Such a dialogue between mediology and hermeneutics has not yet taken place and this is precisely what I intend to start, with a view to the broader set of questions about action in this book.

But where should one start? Consider the following two questions:

- How do ideas become effective, or practice?

- How are cultural products understood?

6 See, for example, Régis Debray, “Un dialogue manqué,” Médium 5 (2005): 116-31, here 116, 129.

7 See Régis Debray, Introduction à la médiologie (Paris: PUF, 2000), Chapter V, "Le conceil des disciplines," in which the author discusses the demarcation of mediology in respect of other disciplines. On these demarcations, cf. Tellez, L'âme et le corps des idées, 174-77.

8 This is the refrain repeated in the subdivisions of the abovementioned chapter by Debray: Why are we not (semiologists, psychologists, sociologists, pragmatists, historians)?

9 The Cahiers de Médiologie (published between 1996 and 2004), was the first mediology journal. Since October 2004 its function has been taken over by Médium.

10 Louise Merzeau, “Ceci ne tuera pas cela," Cahiers de Médiologie 6 (1998): 27-39, citation 28. Unless otherwise indicated, all translations are my own.

11 See Pierre Lévy's attempt at situating mediology in respect of a variety of communication disciplines, and thereby also in the field of all the disciplines, in "La place de la médiologie dans le trivium," Cahiers de Médiologie 6 (1998): 43-58. 
The first question is typically mediological, the second is hermeneutic. Two different points of view, two procedures, two goals. But the two disciplines have a shared interest in that a message that did not belong to anyone becomes someone's, in other words, it is appropriated and thereby becomes meaningful. Both want to know how a message is formed and received. Based on this significant overlap, I would like to single out three areas of shared interest to explore: the subject or agent who is surrounded by technology, which shapes his/her milieu or world (§3), the autonomy of the message or writing and reading (§4) and the opening towards politics $(\S 5)$.

\section{The Technical Milieu and the World of Technology}

At the centre of mediology, Debray places the study of the human being as someone who transmits (l'homme qui transmet). ${ }^{12}$ Where can this human being be found? What are the minimum requirements for transmission characterising the homo transmettans? Transmission takes place where that which is "spoken" (dit) survives or endures because of the way it is spoken, its "speaking" (dire). This coordination of "spoken" and "speaking" stands metonymically for all utterances of meaning, including, for instance, writing or the production of video material. ${ }^{13}$ One may thus reformulate: transmission takes place where the emitted message endures because of the way it continues to be conveyed. Such survival requires that (a) the uttered words or produced images have to be deposited in a support mechanism or prop (support), and (b) that this prop has to be simultaneously transformed by institutions into a carrier or conveyor (vecteur). In short, the "speaking" must be reinforced to become a medium. ${ }^{14}$

12 Debray, Introduction à la médiologie, 2.

13 The two concepts le dire (to say, the saying) and le dit (the said, that which is / was said) are used in widely divergent theories and philosophies in Francophone academic writing. They refer to a meaningful event and the related meaning of the event. I translate them with "speaking" and "the spoken", in quotation marks. For my current purposes, this conceptual pair is useful because it is used by both Debray and Ricœur, and in quite similar ways. However, since they cause quite awkward phrases, I restrict my use of them to the minimum.

14 A detailed survey of Debray's concept of "medium" is offered by Luo Shicha, "Media as Mediation: Régis Debray's Medium Theory and Its Implications as a Perspective," Empedocles: European Journal for the Philosophy of Communication 9, no. 2 (2018): 121-38. Andrea Miconi and Marcello Serra's article “On the Concept of Medium: An Empirical Study," International Journal of Communication 13 (2019): 3444-61 is not dedicated to Debray, but the references to his work in the article are helpful to situate him in the broader landscape of theories of media. 
Correspondingly, a medium, consists, then, of a conveyor with two sides: (a) the prop, as a technical conveyor or expression, i.e. as organized matter (matière organisée); and (b) the institution, as a social conveyor, i.e. materialised organization (organisation matérialisée). Likewise, a medium is both a form of technical artefact and a kind of practice. Thinking through these two aspects of media opens the way to a study respectively of the logistics and the strategy of transmission. ${ }^{15}$ Hence Vandenberghe correctly concludes that "The medium is not [only - EW] a thing, but a dynamic, dialectical praxis and process that interrelates and integrates objects, peoples and texts."16

An additional specification of transmission consists in distinguishing it from communication.

\subsection{Transmission and Communication}

If Debray is concerned with the survival of emitted messages, what is his view on the production and reception of the message? In his mind, this question requires a distinction that is fundamental to his understanding of the mediological enterprise. This distinction consists of contrasting communication (the attempt to transmit a message as effectively as possible over a distance) and transmission (the attempt to ensure that a message will be heard for the longest possible time). Communication is regarded as nothing more than an aspect of transmission. All transmission involves communication, but not all communication transmits, according to Debray. ${ }^{17}$

Not only do I find problematic the way in which Debray makes this basic distinction, I also think that a more careful reconstruction thereof would help us to gain a view on the mutual implication of mediology and hermeneutics. In arguing this point, I stay as close as possible to Debray's conceptual frame. Let us launch this reconstruction by examining what one may consider the most minimal instance of transmission.

Given the way in which Debray made the communication/transmission distinction, there is nothing obvious about my counterclaim that the most basic,

15 Cf. Debray, Introduction à la médiologie, 127; Régis Debray, Transmitting culture, trans. Eric Rauth (New York, NY: Columbia University Press, 2000), 10-15.

16 Vandenberghe, "Régis Debray and Mediation Studies," 29.

17 So important is the communication/transmission distinction thus made that Krämer presents her whole introduction to Debray from this perspective, cf. Sybille Krämer, Medium, Messenger, Transmission: An Approach to Media Philosophy (Amsterdam: Amsterdam University Press, 2015), 63, likewise 77 . However, she does not subject this premise to critical examination. 
minimal transmission phenomenon can be found where two people are speaking to each other, or that dialogue or communication in the physical presence of another always involves transmission, and that if we wish to understand what transmission is, we first have to learn to recognize transmission in communication. In order to justify my claim, it is necessary to explore this minimal scenario carefully. At the core of this phenomenon of minimal transmission is a message: that which is "spoken". By speaking, a person deposits this message in a prop which conveys it to another person. In this case, the prop, on the speaker's side, is the language, which was not invented by the interlocutors, the ability to inflect verbs correctly, practices of courtesy, skilful accentuation and so forth, while on the recipient's side it is the ability to listen, concentrate, understand the type of language or register used, remember, etc. Finally, the two people involved in the conversation form a micro social conveyor that transmits the content of the message and the code used for transmission. The existence of the aforementioned code has already been ensured by the surrounding society and those involved in the conversation are participating in the survival of this code by using it for their mutual communication. Therefore, by communicating a message, the two participants in the conversation are explicitly taking part in the transmission of that message and are implicitly transferring the ability to communicate and receive a message.

\subsection{Transmission in the Mnemosphere}

This simple examination of a situation of dialogue already suffices to raise questions about the mediological resistance to thinking of communication as a transmission event. ${ }^{18}$ It would even become impossible to deny the transmission dimension of communication, by situation communication, as Debray does, within the broader context of mediaspheres. ${ }^{19}$ In Debray's work, a mediasphere is defined as an enormous socio-technical milieu of transmission. Mediaspheres correspond with stages in the technical development of humanity; the logosphere, the graphosphere and the videosphere (the three mediaspheres discussed in detail by Debray), which are historically telescoped into each other. In Introduction à la médiologie, further reference is made to Louise Merzeau's hypothesis of a hypersphere that would be the full development of the video-

18 Even though Debray would have to agree with my analysis - cf. Régis Debray, Cours de médiologie générale (Paris: Gallimard, [1991] 2001), 24.

19 See, for instance, Debray, Transmitting Culture, 103-104, 115-16. 
sphere, ${ }^{20}$ but this was later more completely expounded by Debray in collaboration with Merzeau. ${ }^{21}$ My point about communication as transmission could be substantiated further by due consideration of the mnemosphere - identified but, strangely, neglected by Debray. ${ }^{22}$

The mnemosphere, which only makes its appearance fairly late in Debray's mediological discourse, is mentioned only in passing and disappears quickly from his agenda. ${ }^{23}$ This sphere does not receive the attention it deserves - for instance, one searches in vain for the type of table used to describe other mediaspheres - and there is no justification for this oversight. We are simply informed that, following a vague period of hominising, the logosphere appears as "the period that is introduced by the discovery of the technique of writing". ${ }^{24}$ Each time, a mediasphere is opened up by a technical invention, and Debray urges us to agree that "the phenomenon of technique [...] does not start [...] with electronics, not even with typography, but with the first forms of writing and the first readings". ${ }^{25}$ One might have been able to agree with this contention, if "writing" and "reading" were to be understood in the very broad sense that I use in §2, according to which all technical artefacts are inscriptions that lend themselves to reading and being read (in which case, Debray's claim would simply amount to an analytical truth), but as a historical indication, the claim is simply not true. Debray neglects, amonst other things, the technical dimension of communication in physical presence (although he is not unaware of it) and does not engage with the techniques of the body. These techniques are essential to an understanding of the performative and transmitting nature of communication, which is the most important socio-technical conveyor of the mnemosphere. Hence the significance of reflecting on this mediasphere in the context of the question of the relation between communication and transmission.

In the mnemosphere (in the socio-technical milieu prior to the development of writing on which the logosphere is based), transmission occurs mainly in dia-

20 Debray, Introduction à la médiologie, 45.

21 See Louise Merzeau and Régis Debray, "Médiasphère," Médium 4 (2005): 146-52.

22 Very revealing of this inexplicable neglect of the mnemosphere is the absence even of this term in authors who nevertheless discuss Debray's mediaspheres: cf. Bolouri, Medial Transformations, 162; Shicha, "Media as Mediation," 128; Vandenberghe, "Régis Debray and Mediation Studies," 35; and Melinda Turnley, "Towards a Mediological Method: A Framework for Critically Engaging Dimensions of a Medium," Computers and Composition 28, no. 2 (2011): 126-44, here 130.

23 See Debray, Introduction à la médiologie, 44.

24 Merzeau and Debray, "Médiasphère," 147.

25 Debray, Cours de médiologie générale, 26. 
logue and other forms of direct communication, for example, oral traditions, dances, ceremonies, decorating practices, etc. In the mid-1990s, I attended the inauguration of a Venda chieftain named Stalin Boy. On that occasion, we listened to a recital of Venda history going as far back as six or seven hundred years: centuries of oral transmission of history - the most valuable source for contemporary historiography covering the distant history of a part of the world where methods of transmission were disastrously affected by progress in other mediaspheres. ${ }^{26}$ In the long term, the success of the other mediaspheres in contrast to the mnemosphere was catastrophic for the transmission of forms of socialization, ideas regarding authority, crafts, moral values, etc. which were transmitted via the mnemosphere. The mnemosphere should not be neglected; it still exists alongside the logo-, grapho- and videosphere, and, arguably, the hypersphere. The messages transmitted through the mnemosphere are considerable. We can think about the wearing of clothes, make-up and adornments, smoking, knowledge of edible plants, the practice of music, sexism and the idea of the supernatural, to name but a few of the most important messages whose continued existence will increasingly be ensured by other forms of transmission. This first mediasphere that preceded the development of writing is therefore of paramount importance for the entire mediological project. For the purposes of the current argument, it confirms the transmitting dimension of communication. At a later stage, we will see that the transmission in communication can be explained by the fact that spoken language has a "text-like" dimension, which accords it a form of autonomy, on the basis of which it can function as a medium.

My insistence on the transmitting character of all types of communication should not be seen as a contradiction of the communication/transmission distinction maintained by Debray (on the contrary, I maintain it explicitly in $\S 2$, below). However, it is important not to look for transmission only in the more technologically impressive forms in which it appears. Just as we have found homo transmettans in dialogue, he/she is also present in numerous interactions which involve implicit or explicit learning. Here the basic phenomenon is the techniques of the body (Mauss) or the habitus (Bourdieu). ${ }^{27}$ All artefacts are mnemotechniques, and, in general, artefacts tend to impart a mnemotechnical

26 Further on oral tradition, cf. Okolo Okonda and Jacques Ngangala Balade Tongamba, Introduction à l'histoire des idées dans le contexte de l'oralité: théorie et méthode avec application sur l'Afrique traditionnelle (Louvain-la-Neuve: Academia-L'Harmattan, 2018).

27 Also see Debray, Introduction à la médiologie, 122: "The human body remains the first and last mediator of meaning." On the technical aspect of the body in Mauss and Bourdieu, cf. Ernst Wolff, "Technicity of the Body as Part of the Socio-technical System: The Contributions of Mauss and Bourdieu,” Theoria 76, no. 2 (2010): 167-87. 
effectiveness to the body. In the extension of techniques of the body, which include the most basic forms of communication, the transmission of all the other techniques can be revealed. In this regard, clothes can serve as a useful paradigm.

\subsection{Clothes: Transmission and Understanding}

Almost every single technical artefact transmits something, even if it only the possibility of using natural objects in a technical way. My point is not to simply rephrase McLuhan's "the medium is the message"28, but to give a basic phenomenological description of the transmitting quality of technical artefacts, a description which should allow us to see the overlap between and validity of the hermeneutic and mediological view on it. Let us hone in on this issue.

Through their transmitting character, technical artefacts create sociocultural ties. The following observation by Jean-Pierre Séris about clothes highlights this point:

Clothing is a perfect example of the dialectic of necessity and exigency that takes place in technical production. To the object responds a world that is not reduced to the material world, but is a humanized world, the social and historical world, spoken and written. Clothing and gesture introduce the individuals into this world. ${ }^{29}$

This observation is of considerable importance to understand why clothes are a paradigmatic example of objects invested with socio-historical meaning. Clothes may satisfy physical needs, but at the same time they offer an entrance to that which is not only physical but human, in other words historical, social and meaningful. Furthermore, I argue that clothes are not only objects, but an extension of the wearer's body. This allows them to be both medium and message, which means that wearing clothes therefore amounts to transmitting and simultaneously signifying and understanding. On which grounds can these claims be made?

Clothes are vehicles for messages (for instance, of cultural belonging, social status, a protocol to express resistance to established values); they are the technical props (e.g. this specific shirt; that specific hat) that are mobilised to become a medium by a social wearer involved in the transmission (e.g. the social

28 On the convergences and divergencies of Debray with regard to McLuhan, see Shicha, "Media as Mediation," 124-26.

29 Jean-Pièrre Séris, La technique (Paris: PUF, 1994), 68. 
consensus regarding the proper way to clothe yourself in different situations, penalising practices for ignoring taboos with regard to what is considered appropriate). But to wear and see clothes is also to understand (e.g. I see myself as belonging to this cultural group and other people identify me as such; I understand that the event is formal and that the concert is an elegant occasion which I help to create through my dress; I present myself as sporty to the woman I am trying to impress and she sees me as either genuine or artificial). Clothing inserts wearers into a milieu of media that transmit cultural values and ideas; at the same time they insert them into the totality of references to which we as people who understand are open and which, in phenomenology is referred to as the world (in the rest of this book I use the term "world" in this specific sense). The fact that there is not an explicitly formed message in each case does not detract from the fact that something is being transmitted, and that whatever is being transmitted (and its context) is understood.

\subsection{No Mediology without Hermeneutics. No Milieu without a World}

I have now (a) questioned Debray's articulation of the communication/transmission distinction, (b) explored the mediological significance of identifying transmission in all communication, with reference to the mnemosphere and (c) demonstrated the mutual implication of transmission and understanding with the example of clothing. There is a very good reason why I allowed myself this space: I needed to show how the core concern of hermeneutics emerges logically from the very conceptual framework of mediology. ${ }^{30}$ It may now be safely claimed that it is impossible to see the person as transmitter in the person wearing clothes unless he/she is also recognized as the person who understands. The person who understands is the one who continuously sees and understands everything around him/her, either consciously or unconsciously. A part of what is understood, often the largest part, is what is being transmitted. In other words,

30 I would therefore recommend caution when reading Krämer's claim that "[w]hat Debray achieves with this approach is that he does not need to pit matter against ideas [...], but rather he is able to trace the interconnection of both. Wherever culture is found there is obviously both and if you will - the traditional, hermeneutic-semiological dematerialisation, which proceeds from the tangible to the intangible, is thereby put in its relatively proper place" (Krämer, Medium, Messenger, Transmission, 65). Nor is Debray able to explore fully the passage "from the tangible to the intangible" (i.e. reading), nor does the categorical tag of "dematerialisation" apply to the hermeneutics of Ricœur. 
each milieu or sphere that is created by people who transmit also contains a world thanks to people who understand that milieu and who understand themselves through that particular milieu. Because people understand more than the isolated transmitted message (they also understand that which surrounds the transmission, subject as it is to changing circumstances), the meaning of the transmitted message changes along with the changes in context of its reception. And that is why the institutions and other social conveyors that watch over the transmission are compelled to react by adapting their methods and means of transfer in as far as they strive to stabilise the message. If people, unlike animals, do not only communicate but also transmit, ${ }^{31}$ and if "I am my milieu", ${ }^{32}$ it is possible simply because people do not merely have a situation, but also a world, ${ }^{33}$ or rather, belong to a world. Our milieu is like an enormous garment that leads us into the world and clothes us with meaning, even if (as with clothes) we are often not aware of it.

Belonging (appartenance) is the condition of the human being as the one who understands, according to Ricœur's hermeneutics. Before we examine what this means for Ricœur (see §2), allow me to explore this point first with a view to clarifying its mediological significance. At any given moment, a human being understands and understands him-/herself in a milieu that calls forth his/her world. People bathe in meaning to which they are open, together with others. Different milieus support different worlds: the world of the home, the world of work, the world of recreation, etc. Technical artefacts represent an enormous part of the milieu. In reality, any object can be a prop for signs, and I cannot agree with Debray's assertion that there is no transmission in the interaction with all technical objects. ${ }^{34}$ The bath and the fork (Debray's examples of non-transmitting artefacts) are mnemonics (mnémotechniques as the French aptly say) which, in coordination with social conveyors, are the media of messages about shame, cleanliness, hygiene, or an understanding of food and good manners (see the discussion of this below).

31 Régis Debray, “Technique,” Médium 3 (2005): 162-69, here 164. The author of the particular column is not named, but it is probably Debray.

32 Debray, Introduction à la médiologie, 93.

33 Paul Ricœur, Du texte à l'action. Essais d'herméneutique II (Paris: Editions du Seuil, 1986), 211 / Paul Ricœur, From Text to Action: Essays in Hermeneutics II, trans. Kathleen Blamey and John Thompson (London: Athlone, 1991), 149.

34 See Régis Debray, "Histoire des quatre M,” Cahiers de Médiologie 6 (1998): 7-24, here 20. 
The understanding human is an embodied being and understands, above all, with his/her body. ${ }^{35}$ This body gives specificity to one's understanding, which, however, is never solely one's own. It is not one's own in as far as it is through interaction with other people and the surrounding media that one has learned and continues to learn to understand. It is because people understand, and because in their own way they belong to their milieu and their world, and because their understanding constitutes them as social beings, and because as social beings they simultaneously participate in the construction of the existence of society, that people can transmit, knowingly or unknowingly. At the same time, the understanding belonging to the world through complex techniques of the body can only be understood if it is constituted through transmission. One therefore cannot transmit if one does not also have an understanding ${ }^{36}$ of that which is being transmitted: first, one understands in one's capacity as a social conveyor accompanying the transmission, and second, one understands through one's belonging to, or appropriation of, that which is being transmitted.

The sphere of media, as a gigantic milieu consisting of numerous means of transmission, is therefore the socio-technical dimension of the world. However, the world is always larger than the mediasphere. This is of great importance to mediology, since people's understanding of their worlds always has an impact on their reception of mediated messages. This is why transmission always involves transformation. The struggle for the survival of the emitted message requires modifications of the media by which it is transmitted, in the form of mediological innovations that inevitably lead to the metamorphosis of that message. (In Chapter 3, §5, I explore this as an instance of the technological paradox.)

By establishing the relationship between mediology and hermeneutics, the mediologist should obtain a better understanding of our belonging to a mediasphere, and the socio-technical transmission of understanding is clarified in turn for the hermeneuticist.

35 As has been so carefully described by Merleau-Ponty. Through the techniques of the body, understanding depends on transmission in the same person - a baby's nervous system remains underdeveloped until it is developed by the involvement of those in whose care it is, in other words through songs, dances, jokes, etc., which are cultural products that are supported by techniques of the body and other communal techniques. I owe this insight to Jörn Rüsen.

36 "An understanding” obviously does not remotely imply "full comprehension". 


\section{Autonomy and Appropriation}

The preceding exposition has brought to light how human beings simultaneously belong to mediaspheres and to worlds of meaning - spheres and worlds that are mutually dependent. In order to emphasise the way in which people are surrounded by milieus and worlds all the time, I have highlighted the overlap between communication and transmission in practice. However, the difference between the two cannot be ignored without damaging our understanding of both transmission and interpretation. What is at stake here is the autonomy of the medium (seen from the mediological perspective) or of the text or writing (from the hermeneutic perspective) in respect of the situation in which the message was originally formed. ${ }^{37}$

Mediology and hermeneutics both distinguish equally between "speaking" and the "spoken". The mediologist asks how the "speaking" makes it possible for the "spoken" to survive - how the "spoken" succeeds in being received later by way of its socio-technical "speaking”. The hermeneuticist asks how the "spoken" that has been detached from its milieu of living meaning and acquires its own mode of existence in the socio-technical "speaking" can be absorbed in the meaning for someone, which is how it can be appropriated as having sense. Let us now look at the connection from the perspective of hermeneutics. Paul Ricœur serves as our reference.

The hermeneuticist does not strive only to learn more about the phenomenon of understanding, but also about interpretation. Here, understanding refers to the spontaneous, often unintended grasp which is constitutive of belonging to a world of meaning, while interpretation refers to the second order capacity of reflecting on understandings. This means that interpretation requires a distancing or distantiation ${ }^{38}$ [distanciation] with regard to one's belonging to the world of meanings. Distantiation ${ }^{39}$ thematizes what is understood and is only possible if that which in this way becomes the object of interpretation is supported by

37 In Chapter 2, $\S 3.2$ (Point 1) autonomy is discussed further and argued to be a characteristic of technical artefacts in general.

38 The English translation of From Text to Action writes "distanciation”. I follow Oxford English Dictionary which writes "distantiation".

39 Distantiation is the hermeneutic variant of the phenomenological reduction. One would be able to identify a mediological version in Debray's work (only in the spirit of the text, since the letter of the text will object to the somewhat scholastic nature of the phenomenological method), namely in Debray, Introduction à la médiologie, 48, where the author uses it to describe how the understanding of spontaneous participation in a mediasphere could, as it were, be placed in brackets by a disturbance of the normal functioning of that sphere. 
some or other medium. According to Ricœur, the "original trait" (trait primitif) of distantiation is discourse: verbal expression, or simply putting things into words. In discourse someone says something to someone. Thus discourse forms a dialectic of an event that occurs and which is understood as meaning. ${ }^{40}$ This is equally valid for spoken and written discourse (which, in Ricœur's opinion, both represent archetypes of discourse). Thus a situation develops that is paradigmatic for hermeneutics: written text that must be read, or more generally formulated, inscription that has to become an event of meaning again.

If we consider spoken discourse as a medium for the transmission of a message, as we did in $\S 3$ (above), it would be possible to note that the message has a certain autonomy even in dialogue. ${ }^{41}$ In this way, the dialogical exchange could be seen, at least partially, as an event of writing and reading, where "writing" is metonymic for an event during which meaning obtains autonomy in respect of its origin, and "reading" is metonymic for any event involving the appropriation of meaning. In dialogue, writing and reading, communication and transmission, are more condensed than in cases with a more elaborate socio-technical structure. But when one has learned to view each of these elements in dialogue, it becomes easier to recognize them in other instances.

\subsection{Discourse as Action}

All discourse emits meaning. However, the event or act of discourse itself exceeds the spoken meaning with its own meaning. To get a good grasp on this fact, Ricœur borrows from the speech act theories of Austin ${ }^{42}$ and Searle, in particular Austin's distinction between three discourse actions: the locutionary act (the fact that something is being said), the illocutionary act (the way in which

40 Cf. Ricœur, Du texte à l'action, 115-17, 123-24 / From Text to Action, 77-78, 81-82.

41 However, Ricœur might not agree - in his expositions on discourse, he emphasises the difference between the spoken word and text. But this seems to me a matter of stressing the autonomy of discourse as a dimension of distantiation. Once this point is granted, one has to accept that there is distantiation in spoken discourse too.

42 Also used by Debray in Introduction à la médiologie, 112, 114. I would like to point out that Ricœur had been working on his own version of a "speech act theory” even before J. L. Austin's famous book, How to Do Things with Words. The William James Lectures Delivered at Harvard University 1955 (Oxford: Clarendon, 1962). See Paul Ricœur, "Travail et parole” [1953], in Histoire et vérité (Paris: Seuil, 1964), 238-64 / "Work and the Word," in History and Truth, trans. Charles A. Kelbley (Evanston, IL: Northwestern University Press, 1965), 197-222. I have commented in detail on this interesting essay in a monograph, Lire Ricœur depuis la périphérie. Décolonisation, modernité, herméneutique (forthcoming). 
something is said) and the perlocutionary act (that which is done or brought about by saying something). ${ }^{43}$ In each of these three modalities by which meaning is produced, speaking is also doing - Austin's book is fittingly entitled How to Do Things with Words, and is aptly translated into French as Quand dire, c'est faire (When saying is doing). This embedding of speech act theory in Ricœur's reflection on interpretation is of the utmost importance for the objective of this chapter, since it creates the hinge between a hermeneutics of text and a hermeneutics of action - the latter opens in turn to the broader theme of my whole book.

According to Ricœur, these three aspects of the action of meaning form a descending hierarchy of the possibility of being captured in writing: ${ }^{44}$ the more speech is doing, the less this act can be inscribed in words. Why is this so? Ricœur does not give us a reason, but Debray may help us to work it out for ourselves. The reason is that from locution to illocution to perlocution, speaking gradually becomes more dependent on other forms of technical support: illocution is concerned with the techniques of prosody; in perlocution everything that is needed to ensure the desired effect on the persons who are addressed is used. From locution through illocution to perlocution, discourse increases in sociotechnical density, which is nothing other than the combination of organized matter and materialised organization (as Debray calls it). Therefore Debray is quite right in claiming that "the object of transmission does not pre-exist the operation of its transmission" 45 - in other words, there is no message without a socio-technical embodiment. However, one should not conclude from this that all dimensions of a message are equally prone to be transmitted equally successfully. If the discourse should not merely be written down, but should remain an effective way of doing things with words, then the discourse has to retain this socio-technical logistics and strategy.

\subsection{Autonomy and the Effectiveness of Symbols}

Ricœur does not investigate further how and in which forms speaking can be doing, ${ }^{46}$ and can continue doing over the course of time, which is exactly where the interest of mediology lies. However, the most general condition for

43 Ricœur, Du texte à l'action, 208 / From Text to Action, 147.

44 Ricœur, Du texte à l'action, 119, 209 / From Text to Action, 79, 147.

45 Debray, Introduction à la médiologie, 18.

46 My comment applies to the texts in From Text to Action. What one can do with words has already been thematized in Ricœur, "Work and the Word" referred to above. 
"continuing to do over the course of time" holds his attention. Informally, this condition is called writing, but it would be incorrect to limit the writing to which Ricœur refers to textual inscriptions. When considering writing, Ricœur thinks about the core features of all forms of inscription. He sees writing as the archetype of all inscriptions, as it informs us about the autonomy of the message mediated by the medium or media.

Autonomy emerges when inscription dislocates the dialectic of the "speaking” event and "spoken" meaning. Inscription has this dislocating effect on discourse regardless of whether the inscription is done orally, ${ }^{47}$ in writing, or visually, or by means of any other socio-technical support mechanism. By being written down, the discourse loses its character as an event, or rather as an event of meaning, and continues its existence merely as potential meaning that can only be realized when a recipient appropriates it again as a message. In more mediological terms, autonomy is the mode of existence of the transmitted message. Through the autonomous medium, the message survives, despite, but also as a result of, its autonomy (a) in respect of its original formulator-sender, (b) in respect of its first milieu of reference, i.e. the socio-cultural circumstances of its production, and (c) in respect of the original addressees. ${ }^{48}$ In other words, the autonomous inscription decontextualises what it has inscribed. It is a transformed version of discourse. In this decontextualised state, the discourse is maintained in practice by that with which Ricœur's understanding of the discourse must be completed: discourse is the event during which someone tells something to someone by means of something. No discourse is possible without organized matter and materialised organization, and without an element of autonomy. That is why I argue that dialogic discourse can also be examined according to the model of inscription and transmission (I once again refer to the above explanation of transmission in communication, §3.1).

Debray is, of course, quite familiar with using the text as paradigm, as the following statement proves: "For the dependence of the spiritual on the material, the history of writing serves as a parable". ${ }^{49}$ If the text can serve as a paradigm or archetype, this can be attributed to the fact that it is the example of the autonomy of the message that can be most easily analysed. I have not forgotten that here the "text" is metonymic for the entire milieu associated with it: the school, the books and newspapers, the libraries, the academies, the publishers, etc. And

47 The idea of "oral inscription" is not a contradiction in terms: all verbally transmitted formulas, narratives, languages, etc., which are at least partially repeatable and recognizable, correspond with this term. Oral history (mentioned above) illustrates this point.

48 Ricœur, Du texte à l'action, $207 \mathrm{ff} /$ From Text to Action, $146 \mathrm{ff}$.

49 Debray, Introduction à la médiologie, 43. 
no one considers neglecting the particularities of the other media, even though they are also regarded as "texts". ${ }^{50}$ In Debray's view, "texts" are that which (a) emanates from a general symbolising procedure (procédé général de symbolisation), (b) uses a social code of communication (code social de communication), (c) is supported by a physical aid, (d) benefits from a distribution system (dispositif de diffusion), ${ }^{51}$ (e) is transmitted together with other "texts" thanks to institutions' efforts to manage transmission; and (f) forms milieus that in turn form groups in the mediasphere. But Debray demands more detail and asks: How and by which means can the transmission of "texts" enable us to do things with them? Or, "How does an idea become a material force?" (in the formulation taken up in the title of Vandenberghe's 2007 article). Debray is explicitly concerned with the effectiveness of symbols. ${ }^{52}$

Ricœur, for his part, is not at all ignorant about the significance of the effectiveness of symbols. In the Introduction we saw the importance he attached to the combination of a "spirituality" and a "technology" - that art which Gandhi mastered so well (see Introduction, §3.1). For this reason, I would not hesitate to venture that the question about the effectiveness of symbols is one of the sources from which his interest in hermeneutics emerged. Be that as it may, in his hermeneutic essays in From Text to Action he is satisfied with not spending too much time contemplating the nature of the means of discourse; he accepts text/writing as a paradigm and moves on to other important questions: how does it happen that that which had been "spoken" is recontextualised, in other words, how does the autonomous discourse become reintegrated into a dialectics of event and meaning, and how does this fact become interpretation? Therefore Ricœur's hermeneutics remains occupied with the effectiveness of symbols, but in a different way.

50 There is therefore no reason to protest, for example, with reference to Debray, Introduction à la médiologie, 161-62, that visual images cannot be interpreted as a written discourse - here we are not ignoring the differences between the media, but we are concerned with pointing out their common characteristic, which is autonomy.

51 Cf. Debray, Introduction à la médiologie, 35.

52 See, for example, Debray, Introduction à la médiologie, the title of Chapter IV - L'éfficacité symbolique. The French "efficacité" embraces both effectiveness and efficiency. If there were an exact English equivalent, I would have used it. Since there is not, I try to distinguish as well as possible in each case which term to use, if not both, taking as my guide the idea that effective transmission requires effective conveyors, and that may be so because they are also efficient, but not necessarily.

Translating "éfficacité symbolique" directly poses another problem: "symbolic effectiveness" could create the misunderstanding if the phrase is contrasted with, say, "real effectiveness". Hence the decision rather to use "effectiveness/efficacy of symbols". 
Whereas Debray places more emphasis on the effectiveness of symbols, Ricœur tends to stress the symbolic aspect of their effectiveness. Mediology examines the ways in which meanings are transformed into media; hermeneutics attempts to decipher the media environment that offers itself as having meaning. Mediology places more emphasis on everything that relates to the text (but not exclusively), whereas hermeneutics emphasises everything that relates to the reading of the text (but not exclusively).

I therefore conclude that there is a symmetrical relation of mutual implication between the hermeneutic and mediological views. There can be no Beethoven without scores, without concert halls, without conservatories, but the scores, concert halls and conservatories remain deadly silent without the performance and the interpretation. Writing and reading go together - for hermeneutics as much as for mediology - since both are interested in the effectiveness of symbols. Reading is impossible without writing, but until writing has been read, it has not transmitted anything. Therefore, when Sybille Krämer paraphrases Debray as saying that " $[\mathrm{t}] \mathrm{o}$ transmit something means to embody the immaterial" ${ }^{53}$ she renders accurately his fundamentally truncated view on transmission, ${ }^{54}$ an error which can easily be pointed out with the hermeneutic means deployed here. No reception, no transmission. ${ }^{55}$

\subsection{On Reception: Reading Texts and Artefacts}

If the inscription suspends the life of the meaningful event, the text remains dead as long as there is no reader to give it life again. Who is the life-giving reader? It is not only the person to whom the message was originally addressed, but any person who gains access to the message, whether consciously or not, intentionally or not. Moreover, a person never reads alone. Ricœur quite correctly

53 Krämer, Medium, Messenger, Transmission, 65.

54 Debray concludes his chapter on symbolic effectiveness with the words: "Mediology as discourse can be summarised as a trajectory of [...] message, medium, milieu and mediation" [" $L a$ médiologie comme discours peut se ramener à un parcours [...] message, médium, milieu et médiation"] (Debray, Introduction à la médiologie, 137 and also Debray, "Histoire des quatre M"). One might ask whether he does not perhaps stop too soon on his trajectory. The transmission trajectory does not lead anywhere unless appropriation takes place.

55 In fact, one could see how Debray fails on this point, by considering his own description of Glen Gould's reception of Bach - cf. discussion by Constantina Papoulias, "Of Tools and Angels: Régis Debray’s Mediology,” Theory, Culture \& Society 21, 3 (2004): 165-70, here 168-69. 
points out that "every reading of a text always takes place within a community, a tradition, or a living current of thought, all of which display presuppositions and exigencies - regardless of how closely a reading may be tied to the quid, to 'that in view of which' the text was written." 56 The message is read by a reader who participates in a social formation of readers, who keep an eye on what he/she reads and influences his/her way of reading it. Stated in more mediological terms, the institution that changes the deposited meaning into a conveyor does it by reading and by transmitting and/or examining the way in which meanings should be attached. Reading means making the text one's own or interpreting it. If the "effectiveness" of "the effectiveness of symbols" means anything, it is to be sought in the appropriation of meaning. The purpose of transmission is appropriation, and without appropriation transmission remains unaccomplished.

Through appropriation the autonomy of the message is dissolved and the dialectic of the event of meaning and the meaning itself is restored. The message again says something to someone, but this reception is subject to the receiver's specific socio-cultural context and world. It is therefore inevitable that what the transmission delivers to be understood is simultaneously transformed as a result of the circumstances in which the transmission takes place. Appropriation is always taking place, albeit to different degrees, through an active intervention called reading. Here we again have a paradigmatic word that joins together a large number of appropriations, whether intended or not, where the rejection of the message is merely a derived form of reading. To substantiate this claim, let us look at the appropriation of the meaning of technical artefacts in general.

In my opinion, it is possible to identify three types of meaning when reading or appropriating any technical object or transmission medium. ${ }^{57}$ I derive all three from Ricœur's textual hermeneutics:

1. Comprehension through use. Let us look at the example of the fork: I appropriate the fork by using it to eat with, regardless of whether this happens consciously or unconsciously. At the same time, I appropriate a series of re-

56 Paul Ricœur, Le conflit des interprétations. Essais d'herméneutique I (Paris: Seuil, [1969] 2013), 7 / The Conflict of Interpretations. Essays in Hermeneutics, trans. Don Ihde et al. (Evanston, IL: Northwestern University Press, 1974), 3.

57 The last two of these together form the dialectic of reading, as analysed by Ricœur (Du texte à l'action, 163 / From Text to Action, 113). If I slightly adapt his scheme, it is to place his ideas in a context in which technical objects constitute the "text”. In other words, the three types of appropriation as I describe them (which are in essence reconcilable with Ricœur's textual hermeneutics) are developed in the direction of a hermeneutics of technique. This theme is developed further in Chapter 2, §3. 
lated objects that belong to the milieu (see 2.) and the world (see 3.) of the fork.

2. The explanation of the way in which apparatus and devices work, i.e. the literal or direct technical references involved in such artefacts. Thus one can explain how the fork works by referring to the materials from which it was manufactured, its intended relation to other cutlery, the differences between different kinds of forks, the ergonomic or aesthetic logic of its design, its hygienic maintenance, etc.

3. The interpretation of the world of the artefact, ${ }^{58}$ i.e. of the myriad of meanings the artefact and its milieu call to mind. In a certain sense, I dress myself with my forks, as with my clothes. The forks convey a meaning of which their designer is not the (only) author and which cannot be reduced to their direct reference; that is the meaning of the reader who interprets him-/herself in relation to the object. ${ }^{59}$ Here I am concerned with interpretation not only in relation to a fork, but also in relation to the entire milieu into which the fork is integrated. Simultaneously, this involves an interpretation by the reader as being shaped for it through my belonging to a tradition of interpreters. ${ }^{60}$ Thus a communal bond of ideas and values is created between the forks and their users and is also transferred and transformed. The work of the hermeneuticist is to explain "the type of being-in-the-world unfolded in front of the text"61 and also before everything that has the textual structure that I described here. This world is always a mixture of intentionally transmitted meanings and of particular or contingent interpretations within a specific historical context. We will study the hermeneutic circle of the interpretation of technical means in more detail in the next chapter (see §3).

If this is valid for that which apparently does not carry any message (such as the fork), it is even more valid for newspapers, radio, television, the internet and social media. All the media elicit an understanding appropriation that removes the autonomy of the message and gives new meaning to the message. But the initial understanding can also be enhanced through explanation. A typical element of Ricœur's hermeneutics is the conclusion regarding the dialectical coordination

58 I use this phrase as an equivalent to Ricœur's “the world of the text” (cf. e.g. Ricœur, Du texte à l'action, 125-27 / From Text to Action, 84-86).

59 Compare with the way in which the reader interprets him-/herself in front of a text, according to Ricœur (Du texte à l'action, 128 / From Text to Action, 86).

60 Think how people could say, for instance, “We don't eat with our hands like barbarians” or "The Thompsons could really have taken out their best silver for the occasion...".

61 Ricœur, Du texte à l'action, 128 / From Text to Action, 86. 
between explanation and understanding in the act of reading: the more we explain, the more we understand (expliquer plus, c'est comprendre mieux). ${ }^{62}$ Explanation strengthens and mediates understanding through the study of the internal functioning of a particular message in its autonomy. ${ }^{63}$ Explanation helps us to re-understand our appropriation of a message, which in turn advances our interpretation of what we ourselves are, of what we were made to be by our socio-technical milieu and of the extent to which such a reading of ourselves is possible.

\section{Vigilance and Politics}

If it is true, for Ricœur as for Debray, that symbols can acquire effectiveness, then we have to ask by whom that effectiveness is used. With a view to achieving which goals is the effectiveness mobilised? At the expense of whom have these symbols become effective, rather than those? It is hard to deny the immediate social critical and political implications of the idea of the effectiveness of symbols. So significant is this socio-political dimension of the hermeneutics of action that I devote the whole Part 2 of this book to it. Still, a number of comments are called for here.

Debray and Ricœur agree that we do not have direct access to ourselves as beings who understand the world and that self-understanding and understanding others are always mediated. ${ }^{64}$ The conveyors of messages that surround us exert considerable influence on our understanding - "machinery transports its own perspective on the world". ${ }^{65}$ That does not mean that we are programmed by our milieu, but rather that the milieu influences the possibilities of our understanding. ${ }^{66}$ One could say that the person who appropriates messages stored in the media has already been appropriated by the milieu to which he/she belongs, and which has taught him/her to accept or reject, distinguish, evaluate, interpret. This is not only because of the predispositions that are needed for the use of technical artefacts and in this way are encouraged in readers and users of each artefact, but also because the institutional conveyor is concerned about the re-appropriation of the autonomous technical conveyors - an appro-

62 Ricœur, Du texte à l'action, 25 / The translation omits this passage in From Text to Action, 9.

63 See Ricœur, Du texte à l'action, 195, 201 / From Text to Action, 138, 142.

64 See, for example, Ricœur, Du texte à l'action, 170 - 71 / From Text to Action, 118-19; Debray, Transmitting Culture, 7.

65 Debray, Cours de médiologie générale, 401.

66 Cf. Debray, Introduction à la médiologie, 88. 
priation that is desired for the long term. Therefore, through reading, understood as a complex socio-technical event (rather than as a private activity), efficient symbols have the ability to influence the way someone understands him-/herself in a particular milieu. The will to influence this reading that people do of themselves is a political reality. This point obviously holds for explicit, linguistic messages; it equally holds for the implicit influence on people through a whole technical milieu, as has been convincingly demonstrated by Foucault. ${ }^{67}$ Politics in the broadest sense is concerned with mediology and hermeneutics, since the core of both disciplines - the effectiveness of symbols in social interaction - constitute the matter of which politics and its means and power are composed.

Admittedly, mediology "does not practise politics" and "morality is forbidden to the mediologist". ${ }^{68}$ Its task is to describe and explain. Nevertheless, "political and moral reflection on the limits, ends and abuses of power will increasingly have to pass through the technical study of the power of means, which would not be a bad definition of our project [that is, of mediology - EW]". ${ }^{69}$ Hermeneutics can be situated in the same way: it is not simply political philosophy, but a spontaneous extension of the hermeneutic project is the investigation into that which occurs politically during the interpretation events, and with a view to interpretation of the connections between narrative, action and the ethical-political complex. ${ }^{70}$ This is amply demonstrated in Ricœur's published Lectures on Ideology and Utopia, ${ }^{71}$ but he also traces the way to such engagement with political matters in From Text to Action and comes explicitly back to it in examining the socio-political dimension of his hermeneutics of the capable human, for instance, in Oneself as Another (Studies 7-9). But for those who have taken his early philosophy seriously (see Introduction), this comes as no surprise.

Mediology and hermeneutics, each in its own way, examine people's position in the socio-technical whole that can never be completely unravelled since it is shaped by people while it simultaneously shapes them. As heirs of Marx on this point, hermeneuticists and mediologists do not believe in the autopositioning (autoposition) of the subject, since subjects are shaped through

67 Notably in Michel Foucault, Discipline and Punish: The Birth of the Prison (New York, NY: Pantheon, 1977).

68 Debray, Cours de médiologie générale, 417 and Régis Debray, Vie et mort de l'image. Une histoire du regard en Occident (Paris: Gallimard, 1992), 506, respectively.

69 Debray, Cours de médiologie générale, 46.

70 See Ricœur, Du texte à l'action, 9 / From Text to Action, xv.

71 Paul Ricœur, Lectures on Ideology and Utopia, ed. George Taylor (New York, NY: Columbia University Press, 1986). 
the mediation of the products of their hands, which also made their hands. ${ }^{72}$ The production of people (and both meanings of this ambiguous expression should be understood) lends itself to two types of interpretation - the practice of recollection of meaning and the practice of suspicion which Ricœur discusses at the beginning of De l'interprétation. ${ }^{73}$ The practising of these two interpretation strategies in the hermeneutics of technical artefacts, and more specifically the hermeneutics of the media, can help us to examine every mediasphere as "a transcendental technique that sets a priori the conditions for the production of meaning and events for whoever wants to use it", but only while bearing in mind "the mastery of the medium over its masters". ${ }^{74}$ The aim is clearly not to draw up a political programme, but rather to assume a stance of vigilance: "Hermeneutics is not the name of a philosophical project that aspires to absolute intelligibility, but the name of a vigilant thinking based on its absence."75

The time has now come for a number of provisional conclusions.

\section{Conclusion}

In this chapter I attempted a first alignment of philosophical hermeneutics with social scientific theory. This was undertaken with the book's aim of clarifying the relation between human capabilities and the means of action in mind, namely by concentrating on the interactions involved in the emission, transmission and reception of messages. On Ricœur's side, I offered a reconstructive reading of his hermeneutics in From Text to Action and an elaboration on the hermeneutics of technical artefacts. Throughout, this was done in tandem with a critical interpretation of Debray's mediology, from which I also drew out some unexplored implications. It would certainly have been possible to work with another author in media studies, but the succession of arguments above suffices to demonstrate the merits of my choice. What are the most important gains from this chapter for the overall argument of the book?

72 See the way in which Cornelius Castoriadis situates Marx's contribution to the philosophy of technique, in Cornelius Castoriadis, "Technique," Les carrefours du labyrinthe (Paris: Seuil, 1978), 221-48.

73 Paul Ricœur, De l'interprétation. Essai sur Freud (Paris: Seuil, 1965), 38-46 / Freud and Philosophy. An Essay on Interpretation, trans. Denis Savage (New Haven, CT, and London: Yale University Press, 1970), 28-36.

74 Debray, Cours de médiologie générale, 440, 437.

75 Jean Grondin, Le tournant herméneutique de la phénoménologie (Paris: PUF, 2003), 115. 
First, critical debate with a sceptic served to dispel doubt as to the rightful place and utility of philosophical hermeneutics in studying human interaction. ${ }^{76}$ From the point of view of hermeneutics, I developed the argument from its very historical core: the understanding of texts. "Texts", we saw, may well be technical artefacts, but we can only grasp what they are as social phenomena if we consider them as an integral part of complex events of human interaction. From the point of view of mediology (the social scientific relevance of which I never questioned), I showed how consistent reflection on its own core concepts compels it to accept and openness to hermeneutic questioning; indeed, that it requires hermeneutics to complete its own work (see the discussion of communication, the mnemosphere and reception). This was not a boxing match in which hermeneutics scored a knockout. Using mediological insights into the formation and transmission of media, and the mediological dimension of technical artefacts and milieus in general, I was able to develop Ricœur's understanding of textual autonomy and reception into an outline of a hermeneutics of technical action and means. This outline is, moreover, in agreement with his own understanding of strategy and technology in his earlier socio-political thought (cf. Introduction, §3).

Second, I need to emphasise that recognizing the symmetrical relation between mediology and hermeneutics is not merely a matter of academic courtesy. For all the importance accorded to hermeneutics in this book, I do not consider it a master paradigm. In order for it to shed its clarifying light on social phenomena, it needs to be used in combination with insights from other social sciences. That Ricœur steadily did so, and that I consider it essential to the research documented in this book, has already been stated in the Introduction ( $\$ \S 1$ and 2). Hermeneutics is, amongst other things, an approach to interdisciplinary integration.

Third, I need to circumscribe carefully the place of everything "technological" in this chapter. In speaking about media of transmission in their full breadth (materialised organization and organized matter) and in considering the transmitting quality of technical means and action in general, we quite clearly

76 In this respect it is not irrelevant to point out that Debray accepted an earlier version of this chapter of my book for publication in his journal, Médium. He placed an editor's introduction on the first page of the article conceding that "[b]etween hermeneutics and mediology, there is evidently proximity and complementarity. The 'dialogue' published in our last issue (Médium nº 5) was too obviously caricatural to give an account of these complex relationships, between sisters who are not enemies but accomplices. Let us thank Ernst Wolff for having reacted appropriately, by identifying important avenues of research to shed light on our common goal: symbolic effectiveness.” Untitled editor's introduction to Ernst Wolff, “Transmettre et interpréter," Médium 6 (January-March 2006): 30 -47, citation 30 (the author is not named, but it is probably Debray). 
enter the domain of a philosophy of technology and of science and technology studies. However, the general sense and objective of the chapter is oriented beyond the interdisciplinary contributions that may come from these disciplines. What is at stake is rather an exploration of social interaction, of which the coordination of human capabilities with means is a central dimension. I call this the technical dimension of action or the technicity of action. With this chapter in mind, it becomes much easier to substantiate the claim that all action has a technical dimension; it even begins to outline the profile of that technical dimension and give an impression of why one would take a specific interest in it.

Fourth, let us reflect again on the core notion of "the effectiveness of symbols". Everything in this chapter speaks for the embeddedness of communication, transmission and interpretation in human interactions. This accords the efforts to bring a message home a pervasive place throughout society. Yet, one limit of this notion should not escape our attention. The question regarding the validity of the message for which efficient symbols are sought has not been addressed, and for a very good reason: neither the elements of hermeneutics mobilised here nor mediology has the competence to deal with this question. The closest we came to this point is to indicate the vocation that both mediology and hermeneutics have for caution or vigilance. Both are animated by the conviction that something is at stake in their research. However, they cannot go further, and in this book I will also keep myself to this delimitation (which is not to say that the question is insignificant!). I will look closer at this point in the "Intermediary reflection".

Fifth, all along it has been assumed that, unless explicitly specified otherwise, the claims made are sufficiently general to apply to all people in all contexts. This holds as much for everything related to the historical genesis of socio-technical systems as it does for the more narrowly defined human interaction with such systems. It holds as much for mediology as it does for hermeneutics. As stated in the Introduction, I do not object to the quest to identify such anthropological similarities. However, it should be evident that openness to the cultural other would make an invaluable contribution in such a quest, both to test the generality of such claims and to suggest other claims.

But this chapter is clearly still very limited in its scope and the task is now to turn much more explicitly to Ricœur's broader philosophy to gain solid insights. 